\title{
SOME NEW TWO-SIDED INEQUALITIES CONCERNING THE FOURIER TRANSFORM
}

\section{Aigerim Kopezhanova, Erlan Nursultanov and LARS-Erik PERsson}

Abstract. The classical Hausdorff-Young and Hardy-Littlewood-Stein inequalities do not hold for $p>2$. In this paper we prove that if we restrict to net spaces we can even derive a two-sided estimate for all $p>1$. In particular, this result generalizes a recent result by Liflyand $\mathrm{E}$. and Tikhonov S. [7] (MR 2464253)

Mathematics subject classification (2010): 46E30, 42A38.

Keywords and phrases: Inequalities, Hausdorff-Young's inequality, Hardy-Littlewood-Stein inequality, Fourier transform, Lorentz spaces, total variation, network spaces, two-sided estimates.

\section{REFERENCES}

[1] M. Dyachenko, E. Liflyand and S. Tikhonov, Uniform convergence and integrability of Fourier integrals, J. Math. Anal. Appl., 372 (2010), 328-338.

[2] M. Dyachenko And S. Tikhonov, A Hardy-Littlewood theorem for multiple series, J. Math. Anal. Appl., 339, 1 (2008), 503-510.

[3] M. I. D'Yachenko And P. L. Ulyanov, Measure and integral, Faktorial, Moscow, 1998, 160 pp. (in Russian).

[4] D. Gorbachev, E. Liflyand And S. Tikhonov, Weighted Fourier inequalities: Boas' conjecture in $\mathbb{R}^{n}$, J. Anal. Math., 114 (2011), 99-120.

[5] A. Kopezhanova And L.-E. Persson, On summability of the Fourier coefficients in bounded orthonormal systems for functions from some Lorentz type spaces, Eurasian Math. J., 1, 2 (2010), $76-85$.

[6] E. Liflyand And S. TikHonov, A concept of general monotonicity and applications, Math. Nachr., 284, 8-9 (2011), 1083-1098.

[7] E. Liflyand AND S. Tikhonov, Extended solution of Boas' conjecture on Fourier transforms, C. R. Acad. Sci. Paris. Ser. I., 346 (2008), 1137-1142.

[8] E. Liflyand And S. Tikhonov, The Fourier transforms of general monotone functions, Analysis and Mathematical Physics, Trends in Mathematics, Birkhäuser, (2009), 377-395.

[9] E. Liflyand And S. Tikhonov, Two-sided weighted Fourier inequalities, Ann. Sc. Norm. Super.Pisa CI. Sci., XI, 5 (2012), 341-362.

[10] E. D. Nursultanov, On the coefficients of multiple Fourier series from $L_{p}$-spaces, Izv. Russ. Akad. Nauk Ser. Mat., 64, 1 (2000), 95-122. (in Russian). Translation in: Izv. Math., 64, 1 (2000), 93-120.

[11] E. D. Nursultanov, Network space and Fourier transform, Dokl. Russ. Akad. Nauk., 361, 5 (1998), 597-599 (in Russian). Translation in: Acad. Sci. Dokl. Math., 58, 1 (1998), 105-107.

[12] E. D. Nursultanov, Network spaces and inequalities of Hardy-Littlewood type, Mat. Sb., 189, 3 (1998), 83-102. (in Russian). Translation in: Sb. Math., 189, 3 (1998), 399-419.

[13] E. D. Nursultanov And S. Tikhonov, Net Spaces and Boundedness of Integral Operators, J. Geom. Anal., 21, 4 (2011), 950-981.

[14] Y. SAGHER, Integrability conditions for the Fourier transform, J. Math. Anal. Appl., 54 (1976), $151-$ 156.

[15] E. M. Stein, Interpolation of linear operators, Trans. Amer. Math. Soc., 83 (1956), 482-492.

[16] E. M. Stein And G. Weiss, Introduction to Fourier Analysis on Euclidean Spaces, Princeton University Press, Princeton, 1972. 
[17] S. Tikhonov, Trigonometric series with general monotone coefficients, J. Math. Anal. Appl., 326 (2007), 721-735. 